\title{
Projections of CMIP5 evaporation data sets under future climate change scenarios and comparison with estimates from the observations over peninsular India
}

\author{
G. PURNA DURGA, A. NAGA RAJESH and T.V. LAKSHMI KUMAR* \\ Atmospheric Science Research Laboratory, Dept. of Physics, \\ SRM Institute of Science and Technology, Kattankulathur, Tamil nadu, India. \\ Corresponding author: lkumarap@hotmail.com
}

\begin{abstract}
Present study commences from the time series analysis of evaporation data sets obtained from the Coupled Modeled Inter comparison Project of Phase 5 (CMIP5) for the study period 1979 to 2100 under the RCP 4.5 and 8.5 emission scenarios over Interior Peninsular region during the Northeast monsoon (October to December) period. Further, a comparative analysis has been carried out with the evapotranspiration (ET) estimated from the Hargreaves and Samani (1982) using the temperature data of India Meteorological Department for the period 1979 to 2005. Our results show that evaporation trends are increasing with more prominence in RCP 8.5 scenario. This increase in evaporation has been attributed to increase in air temperature which is an undisputed fact under future climate change scenario. Different climate models of CMIP5 show mixed response by displaying the positive and negative correlations with the Hargreaves ET over the study region. The results of the study will be useful in understanding the bias between the modeled data sets and the estimates of ET from the observations.
\end{abstract}

Key words: Projection, CMIP5, evaporation, climate change, scenarios, peninsular India

Evapotranspiration is one of the important components in the Earth's hydrological cycle. It plays a key role in estimating the crop growing periods through which the moist status of the crop will be inferred (Sarma and Lakshmi Kumar, 2006; Barbosa and Lakshmi Kumar, 2012). It is also useful to effectively monitor the drought conditions over a region (Niranjan Kumar et al., 2013). However, the direct measurements of evapotranspiration are quite difficult and is highly subjected to many uncertainties. A variety of techniques have emerged since long time to estimate the evapotranspiration by using several input parameters. Depending upon the number of input variables, type of the variables and spatio-temporal resolution of the variables, the accuracy of evapotranspiration depends. Several authors used different methods (Kingra et al., 2002; Jadhav et al., 2015) to estimate the evapotranspiration over India and across the globe. Though these methods are well proven independently, their comparison leads to higher uncertainties due to their selection of input data sets (Purnadurga et al., 2019). In recent times the evapotranspiration estimates from the different reanalysis data sets and satellite measurements are emerged and showed that their variations follow the climatic variations. These data sets can be used for large scale studies such as drought assessment studies, surface water conditions etc.
In view of the increasing radiative forcing levels over the globe, the Intergovernmental Panel on Climate Change (IPCC) has developed the climate data sets for the past, present and future climate scenarios at global scale (Taylor et al., 2012). This evidenced that climatic parameters are going to be altered under the future emission scenarios of RCP $4.5 \mathrm{wm}^{-2}$ and $8.5 \mathrm{wm}^{-2}$, respectively. Many studies reported the future scenarios of principal climatic parameters such as temperature and rainfall over different regions of the globe for different emission scenarios. They revealed that the temperature will show a drastic increasing trend by the year 2100 under the RCP 4.5 and RCP $8.5 \mathrm{wm}^{-2}$ (Chaturvedi et al., 2012). The studies on future trends on the land surface parameters such as evapotranspiration are sparse over Indian context. Also, it ought to see the comparison of evaporation obtained from CMIP5 models and this will help in understating the bias and uncertainties between the two data sets.

In light of above the present study focuses on the evaporation data sets obtained from the 19 global climate models of CMIP5 and their ensemble mean from the year 1979-2100 under RCP4.5 and 8.5 scenarios. Further these data sets are independently compared with the evapotranspiration estimated from the Hargreaves and Samani method (1982) over peninsular India during the 
north east monsoon season. The future ET trends over the study area will be of immense help for agriculture planning and drought monitoring over the study region.

\section{MATERIALS AND METHOD}

The present study makes use of the evaporation data from the Coupled global climate models of the CMIP5 project for the period 1979-2100 on monthly basis. These data sets from the 19 global climate models are available with different grid resolutions and the details of these data sets are given in the Table 1 . The above gridded data sets from all the models have been brought to equal footing of $1^{\circ} \times 1^{\circ}$ grid resolution globally by using bilinear interpolation technique and extracted for the Interior peninsular region $\left(72.5^{\circ} \mathrm{E}\right.$ to $81.5^{\circ} \mathrm{E}$ and $8.2^{\circ} \mathrm{N}$ to $\left.15^{\circ} \mathrm{N}\right)$. Thus, the ET data sets obtained from the 19 models are averaged and represented as the multi model ensemble mean and the same have been studied by analyzing the percentage departures from 1979-2100. The percent departures are calculated by taking the base line period (1979-2005) for the NE monsoon season (October to December). The projections of the anomalies thus obtained for the individual models also plotted to understand the deviations in the ET during the RCP 4.5 and RCP 8.5 scenarios. As the rainfall mechanism is convective during the NE monsoon period and the peninsular India experiences most of its annual rainfall during this period, NE monsoon is considered in the present study (Purnadurga et al., 2019).

The maximum and minimum temperature gridded data sets developed by the India Meteorological Department (IMD) have been used to estimate the evapotranspiration using Hargreaves and Samani method. These data sets are available with $1^{\circ} \times 1^{\circ}$ grid resolutions and are developed based on the quality controlled measurements that are wide spread over India (Srivastava et al., 2012). These data sets are widely used for different applications of the climatic parameters (Purnadurga et al., 2017). The solar extraterrestrial radiation which is essential for the estimation of evapotranspiration (Hargreaves-Samani, 1982) that changes with the latitude and time has been obtained from the website of Santa Clara University, USA, (http:// www.engr.scu.edu/ emaurer/tools/calc_solar_cgi.pl). The following formula has been used to estimate the ET from Hargreaves-Samani method.

$$
\mathrm{ET}=0.0023 \mathrm{R}_{\mathrm{A}}\left(\mathrm{T}_{\mathrm{D}}\right)^{0.5}\left(\mathrm{~T}_{\mathrm{a}}+17.8\right)
$$

Where $\mathrm{R}_{\mathrm{A}}$ is the extra-terrestrial radiation; $\mathrm{T}_{\mathrm{a}}$ is mean air temperature $\left(\mathrm{T}_{\text {Max }}+\mathrm{T}_{\text {Min }}\right) / 2 ; \mathrm{T}_{\text {Max }}$ is Maximum temperature; $\mathrm{T}_{\text {Min }}$ is minimum temperature; $\mathrm{T}_{\mathrm{D}}$ is the difference in maximum and minimum temperature.
The evapotranspiration obtained from the above mentioned method has been averaged over the northeast monsoon period and the same has been used for the period 1979-2005. The ET from the Hargreaves and Samani method and the ET from 19 global climate models have been correlated to understand the linear association between the two data sets. The reason for choosing the Hargreaves Samani Method is due to its simple calculation using the maximum and minimum temperatures along with extraterrestrial radiation. The term $\mathrm{T}_{\mathrm{D}}$ in the formula provides an understanding on the land surface information which includes the status of soil wet conditions and its albedo ( $\mathrm{Li}$ et al., 2018). Further, this method is one of the widely used methods over arid and semiarid areas (Madhu et al., 2014).

\section{RESULTS AND DISCUSSION}

Fig. 1 represents the seasonal mean evaporation $(\mathrm{mm})$ for the northeast monsoon season during period 1979-2100 over Interior peninsular region. It can be seen from the Fig. 1 that evaporation is showing increasing trend during historical (1979-2005) and both future climatic scenarios (20062100). The slopes of increment for epochs 1979-2005 and 2006-2100 of RCP 4.5 and RCP 8.5 are $0.0024,0.0032$ and 0.0041 , respectively. The evaporation increment is doubled for epoch1 (1979-2005) to epoch3 (2006-2100) of RCP 8.5. The mean ET values for entire study period (1979-2100) is $3.28 \mathrm{~mm}$ and $3.32 \mathrm{~mm}$ for both scenarios. The multi model ensemble mean shows the increasing ET reaching $3.41 \mathrm{~mm}$ and $3.51 \mathrm{~mm}$ by the year 2100 while the individual models raisedup to $4.5 \mathrm{~mm}$, respectively. The difference from the multi model ensemble mean to individual performance reveals the height of uncertainties from model to model which might be due to different model physics and parameterization schemes. Maity et al., (2015) studied the monthly evaporation trends over India using CMIP5 data sets for the period 1850-2005 and found the very small decrement in NE region of India, Tamil Nadu and Kerala regions during the all months. In contrast to their results the ET has shown an increasing trend in the present work for the historical period 1979-2005. This increase in evaporation can be related to increasing air temperature over this study region has reported by Madhu et al. (2014). A consistent increase in the mean temperature over peninsular India resulted in the increasing vales of ET (Madhu et al., 2014). The same increasing trend is continued during the two emission scenarios which is again an indication of increasing air temperatures over India due to global warming (Fig. 2). The increasing temperatures in future climate change scenarios over the study region will 
Table 1: Description of the CMIP5 19 global climate models (Taylor et al., 2012)

\begin{tabular}{|c|c|c|c|c|}
\hline S. No & Modeling center & Institute ID & Model name & $\begin{array}{l}\text { Atmospheric resolution } \\
(\text { lat } \times \text { lon })\end{array}$ \\
\hline 1 & $\begin{array}{l}\text { Commonwealth Scientific and Industrial } \\
\text { Research Organization (CSIRO) and } \\
\text { Bureau of Meteorology (BOM), Australia }\end{array}$ & CSIRO-BOM & ACCESS 1.0 & $1.25 \times 1.875$ \\
\hline 2 & $\begin{array}{l}\text { Beijing Climate Center, China } \\
\text { Meteorological Administration }\end{array}$ & $\mathrm{BCC}$ & BCC-CSM1.1 & $2.8 \times 2.8$ \\
\hline 3 & Beijing Normal University Earth System Mode & BNU-ESM & BNU-ESM & $2.81 \times 2.81$ \\
\hline 4 & National Center for Atmospheric Research & NCAR & CCSM4 & $0.9 \times 1.25$ \\
\hline 5 & $\begin{array}{l}\text { Centro Euro-Mediterraneo per } 1 \\
\text { CambiamentiClimatici }\end{array}$ & $\mathrm{CMCC}$ & $\mathrm{CMCC}-\mathrm{CM}$ & $0.75 \times 0.75$ \\
\hline 6 & $\begin{array}{l}\text { Centre National de Recherches } \\
\text { Météorologiques/Centre Européen de } \\
\text { Recherche et Formation Avancéeen } \\
\text { CalculScientifique }\end{array}$ & $\begin{array}{l}\text { CNRM- } \\
\text { CEFRACS }\end{array}$ & CNRM-CM5 & $1.4 \times 1.4$ \\
\hline 7 & $\begin{array}{l}\text { Commonwealth Scientific and Industrial } \\
\text { Research Organization in collaboration } \\
\text { with Queensland Climate Change } \\
\text { Centre of Excellence }\end{array}$ & CSIRO-QCCE & CSIRO-Mk3.6.0 & $1.9 \times 1.9$ \\
\hline 8 & NOAA Geophysical Fluid Dynamics Laboratory & NOAA GFDL & GFDL-CM3 & $2.0 \times 2.5$ \\
\hline 9 & NASA Goddard Institute for Space Studies & NASAGISS & GISS-E2-R & $2.0 \times 2.5$ \\
\hline 10 & Institute for Numerical Mathematics & INM & INM-CM4 & $1.5 \times 2.0$ \\
\hline 11 & Institut Pierre-Simon Laplace & IPSL & $\begin{array}{l}\text { IPSL-CM5A-LR } \\
\text { IPSL-CM5A-MR }\end{array}$ & $\begin{array}{l}1.9 \times 3.75 \\
1.3 \times 2.5\end{array}$ \\
\hline 12 & $\begin{array}{l}\text { Japan Agency for Marine-Earth Science and } \\
\text { Technology, Atmosphere and Ocean }\end{array}$ & MIROC & MIROC-ESM & $2.8 \times 2.8$ \\
\hline 13 & $\begin{array}{l}\text { Research Institute (The University of Tokyo), } \\
\text { and National Institute for Environmental Studies }\end{array}$ & & $\begin{array}{l}\text { MIROC-ESM- } \\
\text { CHEM }\end{array}$ & $2.8 \times 2.8$ \\
\hline 14 & Max Planck Institute for Meteorology & MPI-M & MPI-ESM-LR & $1.9 \times 1.9$ \\
\hline 15 & Meteorological Research Institute & MRI & MRI-CGCM3 & $1.1 \times 1.1$ \\
\hline 16 & Norwegian Climate Centre & NCC & NorESM1-M & $1.9 \times 2.5$ \\
\hline
\end{tabular}

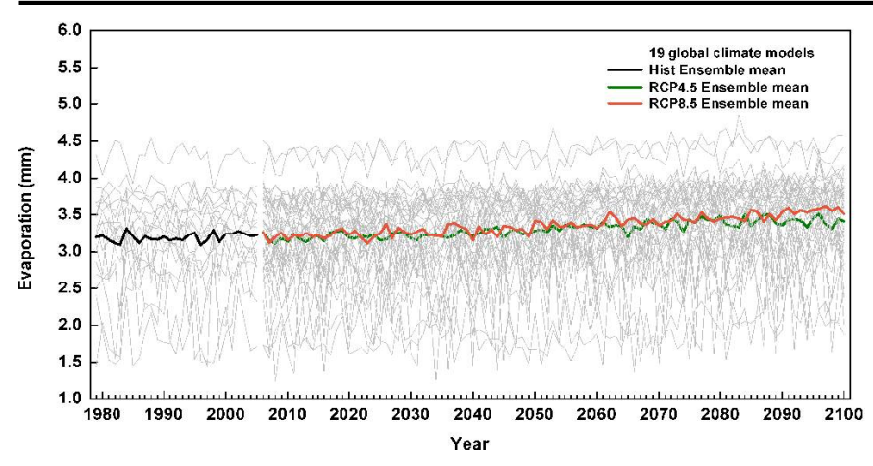

Fig.1: Seasonal mean evaporation from the CMIP5 data sets over Peninsular India during the North east monsoon season for the period 1979-2100. result more surface heating that will supply more latent heating so as to make the surface water to evaporate. The increasing ET trends are analogous to increasing temperature trends over India and reflect the surface dry, moist conditions under the future climate change scenarios.

We made an attempt to study the individual model performance with the ET estimated from the Hargreaves method over peninsular India. Fig. 3 shows the timeseries of seasonal mean evaporation obtained from the multi model ensemble mean and the Hargreaves and Samani method. It can be observed that there is no strong association between 


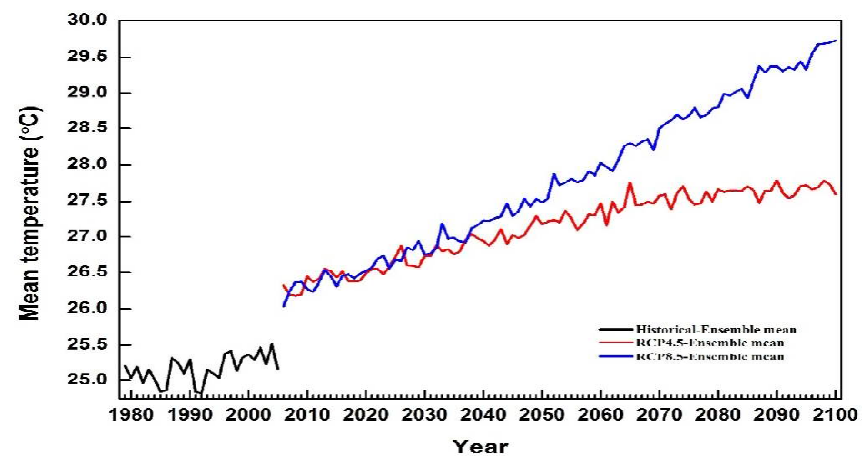

Fig. 2: Seasonal mean temperature from the CMIP5 data sets over Interior peninsular region during the NE monsoon season for the period 1979-2100.
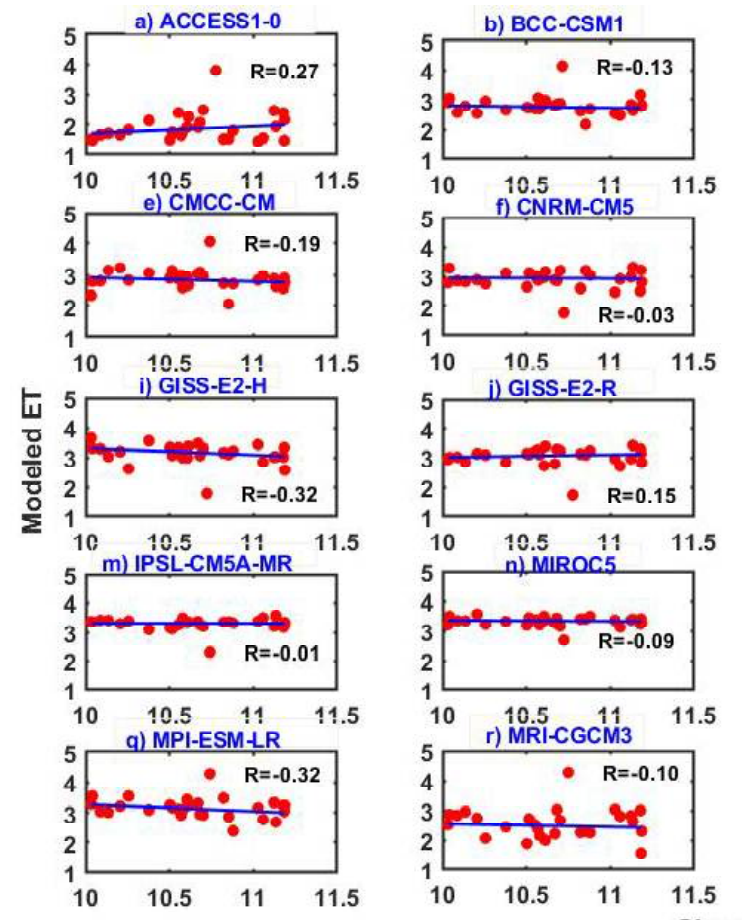

Observed ET
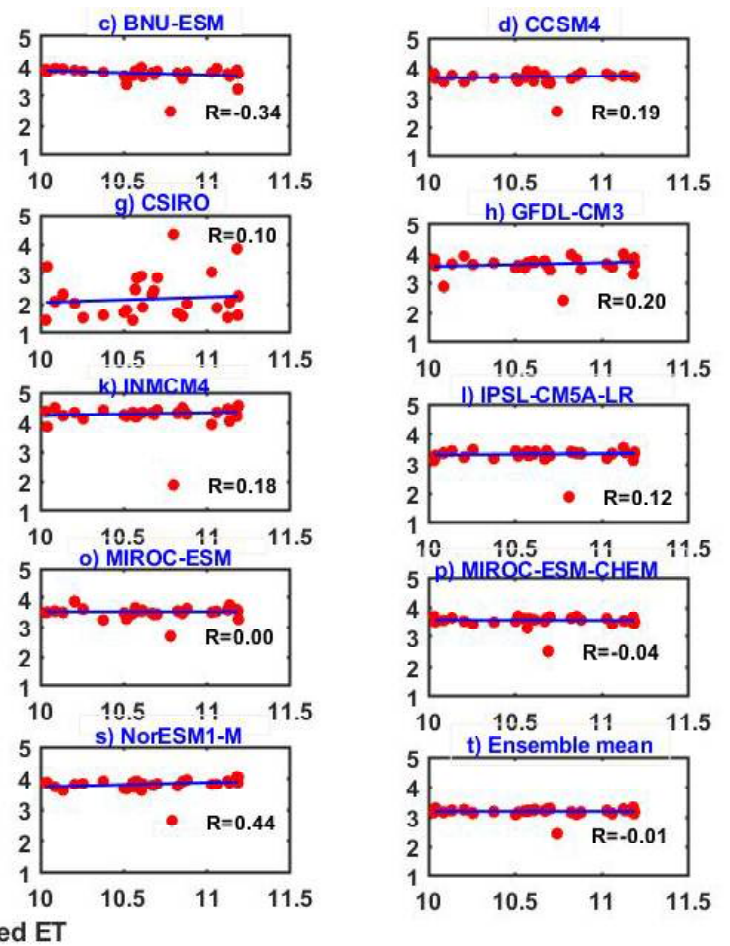

Fig.4(a-t):Scatter plots between CMIP5 modeled evaporation and estimates of ET from the Hargreaves method

the two data sets which is evidenced by their mean bias. The pattern of both data sets is in well agreement in a few years such as 1984, 1995 and 2000. The variability in Hargreaves ET seemed to be high as compared with CMIP5 evaporation. The changes in magnitudes of evaporation of the both data sets are mainly due to the variations in input temperatures that are being considered. Hargreaves ET may be consideredas reference data sets since it uses the temperature data sets of the in-situ measurements that has mentioned in the earlier sections. Also, the topography of the peninsular India is complex which involves more space scale measurements to estimate the near accurate ET. As the global

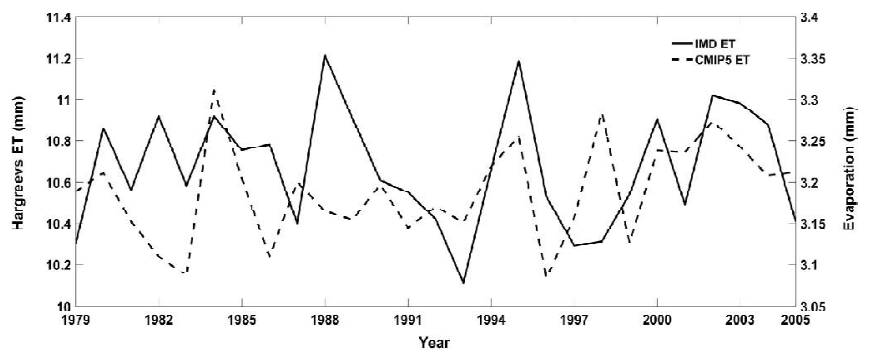

Fig.3: Seasonal mean (OND) evapotranspiration over Interior peninsular region for the period 1979-2005 from IMD (Hargreaves ET) and CMIP5 historical (Ensemble mean) data sets. 
response displaying the positive/negative correlations with statistically significant/insignificant levels. These positive and negative correlations among the data sets of ET were reported by Purnadurga et al. (2019) with the observational and reanalysis data sets. Model physics and uncertainties in temperature along with the other water balance components were attributed to the mixed response among the ET data sets. These models may be helpful in understating the climate variations as they can depict the climatic patterns over different climatic regions.

\section{CONCLUSION}

The present study concludes the following based on the comparative analysis of Hargreaves ET and CMIP5 evaporation data sets. Historical evaporation of multi model ensemble showed very small positive trend over peninsular India for the period 1979-2005. The MME evaporation showed increasing trend and is more prominent in RCP 8.5 scenario by the year 2100 . This increasing evaporation has been attributed to increasing air temperature over the study region. Climate models of CMIP5 show mixed response with Hargreaves ET by displaying the positive and negative correlations. These mixed responses have been attributed to the variations in the input parameters that have been used for estimation of ET.

\section{REFERENCES}

Barbosa, H. and Lakshmi Kumar, T.V. (2012). Strengthening regional capacities for providing remote sensing decision support in drylands in the context of climate variability and change. International perspectives on global environmental change. Intec open publishers.

Chaturvedi, R.K., Joshi, J., Jayaraman, M., Bala, G. and Ravindranath., N.H. (2012). Multi model climate change projections for India under representative concentration pathways. Current Sci., 103(7): 791-802.

Hargreaves, G.H. and Samani, Z.A. (1982). Estimating potential evapotranspiration. J. Irrig. Drain. Engineer. ASCE, 108: 223-230.

Jadhav, P.B., Kadam, S.A. and Gorantiwar, S.D. (2015). Comparison of methods for estimating reference evapotranspiration (ETo) for Rahuri region. $J$. Agrometeorol., 17(2): 204-207.

Kingra, P.K., Kaur, P. and Hundal, S.S. (2002). Estimation of PET by various methods and its relationship with mesh covered pan evaporation at Ludhiana. J. Agrometeorol., 4(2): 143-149.

Laine,A., Nakamura, A. and Nishii, K. (2014). Adiagnostic study of future evaporation changes projected in CMIP5 climate models. Clim. Dynamic., 42:2745-2761.

Li, Z., Yang, Y., Kan, G. and Hong, Y. (2018). Study on the Applicability of the Hargreaves Potential Evapotranspiration Estimation Method in CRESTDistributed Hydrological Model (Version 3.0) Applications. DOI: 10.3390/w11102099

Madhu, S., Lakshmi Kumar, T.V., Koteswara Rao, K., Barboas, H. and Vizayabaskar, V. (2014). Trend analysis of evapotranspiration and its response to droughts over India. Theor. Appl .Climatol., 121(1):41-51.

Maity, R., Aggarwal, A. and Kironmala, C. (2015). Do CMIP5 models hint at a warmer and wetter India in the $21^{\text {st }}$ Century. J. Water Clim. Change,7(2): 280-295.

Niranjan Kumar, K., Rajeevan, M., Pai,D.S. Srivastava,A.K. and Preethi, B. (2013). On the observed variability of monsoon droughts over India. Weather Climate Extremes., 1: 42-50.

Punradurga, G., Lakshmi Kumar, T.V., Koteswara Rao, K., Rajasekhar, K. and Narayanan, M. (2018). Investigation of temperature changes over India in association with meteorological parameters in a warming climate. Int.J. Climatol., 38: 867-877.

Punradurga, G., Lakshmi Kumar, T.V., Koteswara Rao, K., Barboas, H. and Mall, R.K. (2019). Evaluation of evapotranspiration estimates from observed and reanalysis data sets over Indian region.Int. J.Climatol.,39: 1-10.

Samra, A.A.L.N. and Lakshmi Kumar, T.V. (2006). Studies on crop growing periodand NDVI in relation to water balance components. Int. J. Radio Space Phy., 35:424434.

Srivastava, A.K., Rajeevan. and Kshirsagar, S.R. (2009). Development of a high-resolution gridded temperature data set (1969-2005) for the Indian region. Atmos. Sci. Lett., 10(4):249-254.

Taylor, K.E., Stouffer, R.J. and Meehl, G.A. (2012).An overview of CMIP5 and the experiment design. Bull. Am. Meteorol. Soc., 93(4): 485-498. 